\title{
Modeling and Multi-Objective Optimization of Thermophysical Properties for Thermal Conductivity and Reynolds number of CuO-Water Nanofluid using Artificial Neural Network
}

\author{
Amin Moslemi Petrudi \\ Department of Mechanical Engineering, Tehran University, Tehran, Iran. \\ Email:\{amin.moslemi2020@gmail.com\}
}

\begin{abstract}
In nanofluids, due to the small size of the particles, they greatly reduce the problems caused by corrosion, impurities, and pressure drop, and the stability of fluids against sediment is significantly improved. Due to the high conductivity of nanoparticles, with the distribution in the base fluid, they increase the thermal conductivity of the fluid, which is one of the basic parameters of heat transfer. In this paper, properties using experimental data and artificial neural networks, to maximize thermal conductivity, temperature changes, and nanofluid volume fraction of NSGA-II optimization algorithm and also to obtain thermal conductivity values from 154 experimental data, artificial neural network modeling is used. Various indices including R-squared and Mean Square Error (MSE) have been used to evaluate the modeling accuracy in prediction, Reynolds number, and nanofluid thermal conductivity. The coefficient of determination of the relation (R-squared) is equal to 0.9988 , which indicates the acceptable agreement of the proposed relationship with the experimental data. To optimize, the results are presented as a target function, the Parto-front, and its optimal points. Optimal results showed that the maximum thermal conductivity coefficient and the optimal Reynolds number occur in a volume fraction of $2 \%$.
\end{abstract}

Keywords: Multi-Objective Optimization, Parto-front, NSGA-II Algorithm, Nanofluid.

\section{INTRODUCTION}

One of the basic needs in many industries and research projects is to have high-efficiency heat transfer environments. Fluid cooling and heating play an important role in many industrial processes including heat sources, manufacturing processes, transportation, and electronics, and many methods have been reported to increase the rate of heat transfer in these processes. Applications of nanofluids in various fields: automobile industry, engine cooling, radiant fluid, steering suspension fluid, clutches, engine oil, brake fluid, lubricating oil, and greases. Nuclear application, the primary refrigerant in pressurized water reactors (PWR), and rapid safety systems. Renewable energy, to increase heat transfer and the volume of energy received from solar collectors. Defensive, cooling of electronic equipment and weapons, war vehicles, and submarines [1]. There are four thermophysical properties of fluid that change with the addition of nanoparticles to the base fluid. These properties include density, viscosity, thermal conductivity, and specific heat. Different researchers have expressed different opinions about the effect of adding nanoparticles on the values of these properties, but in general, adding nanoparticles increases these properties except for specific heat, which decreases with the addition of nanoparticles. The percentage of this increase depends on various factors such as the volume percentage and properties of nanoparticles, base fluid properties, and temperature. Thermal conductivity is one of the most important factors to study heat transfer. A review of existing research shows that the addition of a small percentage of nanoparticles significantly increases the thermal conductivity of nanofluids compared to the base fluid [2-5]. Also, the thermal

ISSN (Print): 2456-6411 | ISSN (Online): 2456-6403 conductivity of nanofluids depends on parameters such as the composition of the chemical percentage of nanoparticles and nanofluids, the volume percentage of nanoparticles, the shape

and size of particles, temperature [6]. Clarify et al. [7] investigated the feasibility of ANFIS-PSO and ANFIS-GA models in predicting the thermophysical properties of $\mathrm{Al} 2 \mathrm{O} 3$ MWCNT/oil hybrid nanofluid. To evaluate and compare the performance of the models, two statistical indices of root mean square error (RMSE) and determination coefficient (R) was utilized. Based on the results, both of the models can predict the thermophysical properties appropriately. However, the ANFIS-PSO model had a better performance than the ANFISGA model. Finally, the studied thermophysical properties were developed by the trained ANFIS-PSO model. Abdollahi et al. [8] investigated performance characteristics of low concentrations of $\mathrm{CuO}$ /water nanofluids flowing through the horizontal tube for energy efficiency purposes; an experimental study and ANN modeling. An artificial neural network (ANN) with one hidden layer and eight neurons was designed to predict the Nusselt number. The transfer function and training algorithm were respectively the Tansig and the Levenberg-Marquardt. The ANN outputs showed a maximum of $1 \%$ deviation; the R-squared, the mean squared error (MSE), and the average absolute relative deviation (\%AARD) were also 0.9966, 3.1384, and 0.0236, respectively. Amani et al. [9] investigated the prediction of hydrothermal behavior of a nonNewtonian nanofluid in a square channel by modeling of thermophysical properties using a neural network. According to the results, it is found that the friction factor ratio is directly proportional to the temperature and nanoparticle content, while 
it inversely varies relative to the shear rate. The corresponding data disclose that the performance index is directly proportional to the nanoparticle content, especially at the decreased shear rate and elevated temperature conditions. The application of $\mathrm{TiO} 2 / \mathrm{CMC}$-water nanofluid is found to be more favorable for applications with elevated shear rate conditions. Zafar et al. [10] investigated fuzzy modeling and optimization for experimental thermophysical properties of water and ethylene glycol mixture for $\mathrm{Al} 2 \mathrm{O} 3$ and $\mathrm{TiO} 2$ based nanofluids. The effect of these three operating parameters on the mixtures density, viscosity, and thermal conductivity is studied. Applying the proposed methodology resulted in obtaining the best condition that produces the optimal output that can minimize both the density and viscosity and at the same time maximizes the thermal conductivity. Han et al. [11] investigated the multi-objective optimization of the corrugated tube with loose-fit twisted tape using RSM and NSGA-II. The results show that the most significant factor is the linear term of $Y$ for $N u_{c} / N u_{s}$ and $f_{c} / f_{s}$, while that for $\eta$ is the linear term of $R e$. Pareto optimal solution can be obtained with the optimum $N u_{c} / N u_{s}=2.484$ and $f_{c} / f_{s}=3.324$. The corresponding values of the design variables are $R e=4000.08, Y=2.79$, and $C R=0.20$. The optimal design variables against $R e$ are also obtained, which possesses practical significances for designing heat exchanger. Subramanian et al. [12] investigated $\mathrm{TiO} 2-$ water nanofluid in the double-pipe counter-flow heat exchanger for various flow regimes. the results also show that the heat transfer coefficient of the nanofluids at a volume concentration of $0.5 \%$ volume was $15 \%$ higher than that of base fluid at given conditions. The pressure drop of nanofluid was increased with an increase in volume concentration, and it is slightly higher than that of the base fluid. The thermal conductivity and optimization methods of nanofluids are shown Table 1. In the present study, to maximize thermal conductivity and Reynolds (3000 to 18000 ) and volume fraction $(0.0625$ to $2 \%$ ) of $\mathrm{CuO}$ Water nanofluid, laboratory studies and modeling has been performed using the NSGA-II optimization algorithm. The experimental data and the data obtained from the artificial neural network (ANN) are placed next to each other with an acceptable difference, which shows the high accuracy of the relations.

Table 1. Research on the thermal conductivity of nanofluids.

\begin{tabular}{|l|c|c|c|c|}
\hline Author(s) & Nanofluid & Characteristic & Methods & Years \\
\hline $\begin{array}{l}\text { Ebrahimi } \\
{[13]}\end{array}$ & $\begin{array}{c}\text { Al2O3- } \\
\text { EG/W }\end{array}$ & $\begin{array}{c}\text { Parabolic } \\
\text { trough solar } \\
\text { collector }\end{array}$ & ANN & 2018 \\
\hline $\begin{array}{l}\text { Tajik } \\
{[14]}\end{array}$ & Al2O3 & $\begin{array}{c}\text { Thermal } \\
\text { conductivity }\end{array}$ & $\begin{array}{c}\text { ANN } \\
\text { and } \\
\text { GRG }\end{array}$ & 2018 \\
\hline $\begin{array}{l}\text { Bagherzade } \\
{[15]}\end{array}$ & CuO/liquid & $\begin{array}{c}\text { Optimization/st } \\
\text { atistical }\end{array}$ & ANN & 2019 \\
\hline $\begin{array}{l}\text { Rostami } \\
{[16]}\end{array}$ & $\begin{array}{c}\text { SiO2/water } \\
- \text { ethylene } \\
\text { glycol }\end{array}$ & $\begin{array}{c}\text { Thermal } \\
\text { conductivity }\end{array}$ & ANN & 2020 \\
\hline $\begin{array}{l}\text { Moslemi } \\
{[17]}\end{array}$ & Nanotube & $\begin{array}{c}\text { Multi-objective } \\
\text { Optimization }\end{array}$ & RSM & 2020 \\
\hline $\begin{array}{l}\text { Moslemi } \\
{[18]}\end{array}$ & $\begin{array}{c}\text { Water } \\
\text { Hhermal } \\
\text { conductivity } \\
\text { and Viscosity }\end{array}$ & ANN & 2020 \\
\hline
\end{tabular}

\section{GENETIC ALGORITHM}

The genetic algorithm is to find an approximate solution for optimizing models, mathematics, and problems. Genetic algorithm is a special type of evolutionary algorithm that uses evolutionary biology techniques such as inheritance, mutation biology, and Darwin's principles of choice to find the optimal formula for predicting or matching the pattern. Genetic algorithms are often a good choice for regression-based prediction techniques. Genetic algorithm modeling is a programming technique that uses genetic evolution as a problem-solving model. The problem to be solved has inputs that are converted into solutions during a modeled process of genetic evolution, then the solutions are evaluated as candidates by the Fitness Function, and if the exit condition is met, the algorithm terminates. In general, it is an iterationbased algorithm whose parts are often selected as random processes that these algorithms consist of parts of the Fitness Function, display, selection, and change [22].
* Steps before the main loop begins [19]:
1) Initialize population $P_{0}$
2) Sort $P_{0}$ based on nondomination
3) Fitness of an individual is equal to an individuals nondomination level
4) Binary Tournament Selection
5) Mutation and recombination create an offspring population $\mathrm{Q}_{0}$

* Primary loop [19]:

1) $R_{t}=P_{t}+Q_{t}(t=$ generation $)$

2) Sort $R_{t}$ based on nondomination

3) Create $P_{t+1}$ by adding individuals from each level of $R_{t}$ until $P_{t+1}$ is of size $N$

4) Create $Q_{t+1}$ by applying Binary Tournament Selection, Mutation, and Recombination to $\mathrm{P}_{\mathrm{t}+1}$

5) Increment $t$

* Advantages [20]:

$\checkmark \quad$ Explicit diversity preservation mechanism

$\checkmark$ The overall complexity of NSGA-II is at most $\mathrm{O}\left(\mathrm{MN}^{2}\right)$

$\checkmark$ Elitism does not allow an already found Pareto optimal solution to be deleted.

* Disadvantage [20]:

$\checkmark$ Crowded comparison can restrict the convergence.

$\checkmark \quad$ Non-dominated sorting on $2 \mathrm{~N}$ size.

Non-dominated Sorting Genetic Algorithm (NSGA-II) is one of the advanced evolutionary algorithms that requires algorithm parameters to be set up in the algorithm shown in Fig. 1 below [21].

1. Initialize population (pop-size)

2. Cross over $(\mathrm{pc})$

3. Mutation (pm)

4. Max iteration (Gen) 


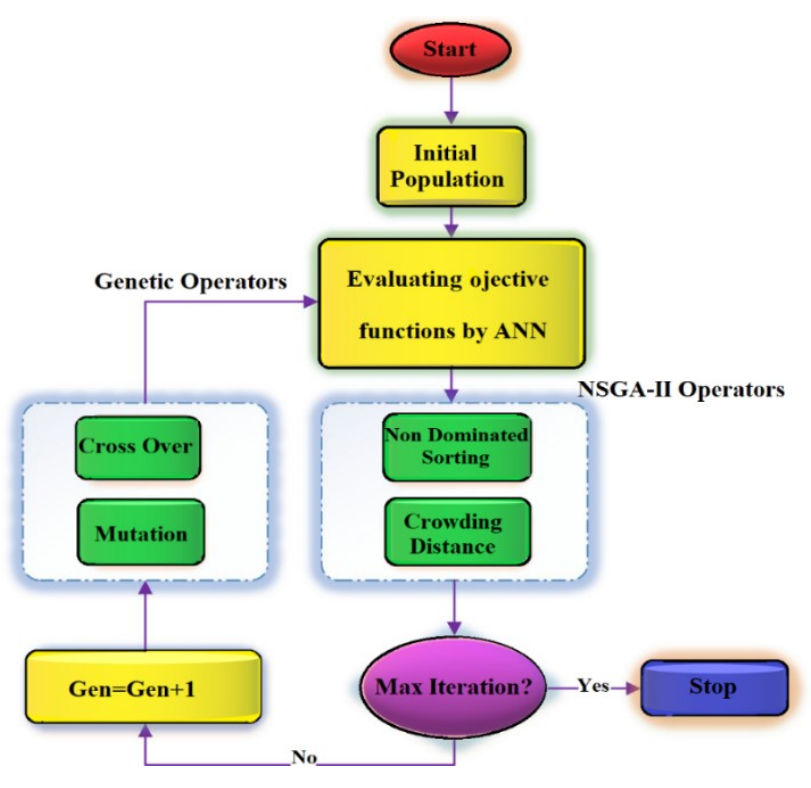

Fig. 1. Flowchart of the optimization algorithm.

In this algorithm, the offspring population $\left(\mathrm{Q}_{\mathrm{t}}\right)$ must first be constructed using the parent population $\left(\mathrm{p}_{\mathrm{t}}\right)$. In this section, instead of using non-dominant offspring solutions, merge $\left(Q_{t}\right)$ and $\left(\mathrm{p}_{\mathrm{t}}\right)$ together and form a population of Rt with $2 \mathrm{~N}$ members and then use a non-dominant categorization to categorize the entire population of $R_{t}$ used, that is, evaluate the current population and divide them into categories with different values. The range will be 1 to $2 \mathrm{n}$. And they will form the next generation. Fig. 2 shows the structure of the NSGA II network [23].

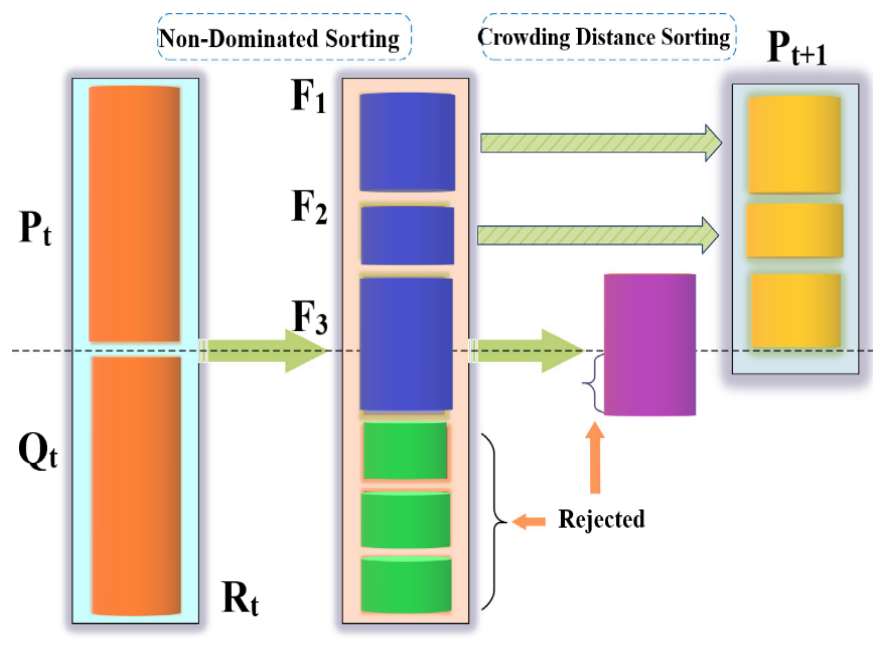

Fig. 2. NSGA II network structure.

Answers $i-1$ and $i-2$ the answers before and after are the answer to $i$, then the distance of the congestion of my answer is as follows:

$$
\begin{aligned}
& d_{i}^{1}=\frac{f_{1}\left(x_{i+1}\right)-f_{1}\left(x_{i-1}\right)}{f_{1}^{\max }-f_{1}^{\min }} \\
& d_{i}^{2}=\frac{f_{2}\left(x_{i-1}\right)-f_{2}\left(x_{i+1}\right)}{f_{2}^{\max }-f_{2}^{\min }}
\end{aligned}
$$

$$
d_{i}=d_{i}^{1}+d_{i}^{2}
$$

Therefore, in a binary tournament, the answer $\mathrm{i}$ is superior to the answer $\mathrm{j}$ if either of the following conditions is true:

$\checkmark$ Rank i is less than rank j $\left(r_{i}<r_{j}\right)$.

$\checkmark \quad$ If answer $i$ is equal to $j$ then answers $i$ is superior to answer $j$ if the answer distance $i$ is greater than the answer distance $j\left(d_{j}>d_{j}\right)$.

A new population of alternatives is formed after the ranking and spacing process, and then by the methods commonly used in genetic algorithms, new populations are generated, new alternatives are generated, and then the previous steps are repeated [23]. Fig. 3 shows the computation of compaction distance in the NSGA II algorithm.

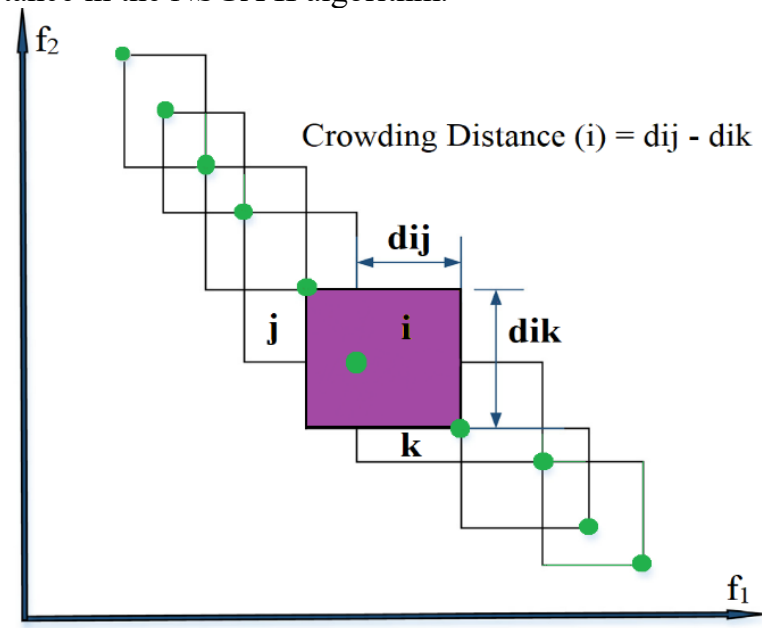

Fig. 3. Calculation of crowding distance in the NSGAII algorithm.

\section{ARTificial NeUral NetWork}

An artificial neural network consists of three layers: input, output, and processing. Each layer contains a group of nerve cells (neurons) that are generally associated with all neurons in other layers unless the user restricts communication between neurons, But the neurons in each layer have no connection with other neurons in the same layer. A neuron is the smallest unit of information processing that forms the basis of the function of neural networks. A neural network is a collection of neurons that, being located in different layers, form a special architecture based on the connections between neurons in different layers. Neurons can be a nonlinear mathematical function, so a neural network made up of a community of these neurons can also be a complete complex, nonlinear system. In the neural network, each neuron operates independently, and the overall behavior of the network is the result of the behavior of multiple neurons. In other words, neurons correct each other in a process of cooperation [24]. A neural network of 10 neurons in the hidden layer and one neuron in the output layer for Reynolds and thermal conductivity models. The number of hidden layer neurons is tentatively determined and given the mean maximum squared error to predict the Reynolds and thermal conductivity and provide a comparison between the neural network and the experimental data. The weights and biases are determined by the Levenberg Marquardt algorithm. It should also be noted that the transfer function in the hidden 
layer of the sigmoid function (logsig) and the linear function (purelin) were performed for the outer layer [23].

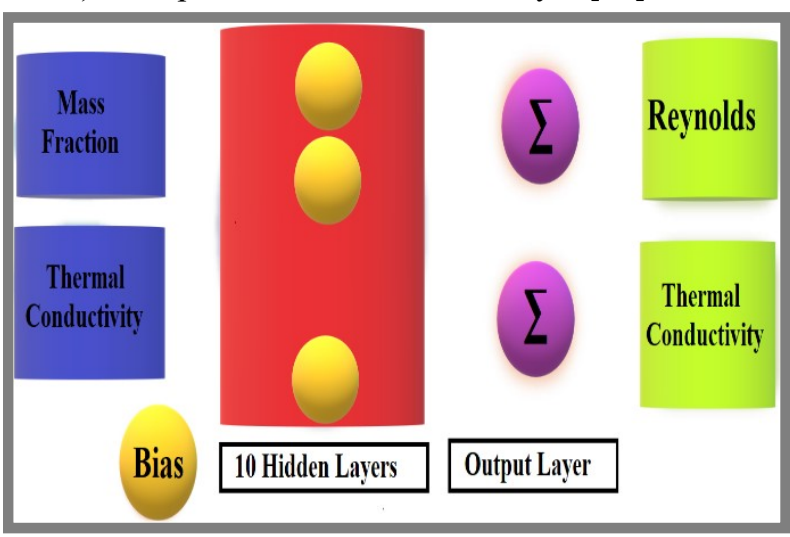

Fig. 4. Structure of neural network.

\section{RESULTS AND DISCUSSION}

To achieve optimal results, the algorithm has been implemented and presented in several stages with different values of the number of members of the population of 50 members and the number of iterations 15 times. To compare the optimization process, the results in the first, fifth, tenth, and Pareto optimization fronts are presented. In this paper, the Nusselt number improves with an increasing volume concentration of nanoparticles as well as the Reynolds number. This increase is due to the higher effective thermal conductivity of the nanofluid as well as the enhancement of the nanoparticle mixing. Fig. 5 performance of ANN model for Nusselt, Fig. 6 performance of ANN model for Thermal Conductivity, Fig. 7 regression of ANN results for Nusselt, Fig. 8 regression of ANN results for Thermal Conductivity, and Fig. 9 Pareto optimal front is shown.

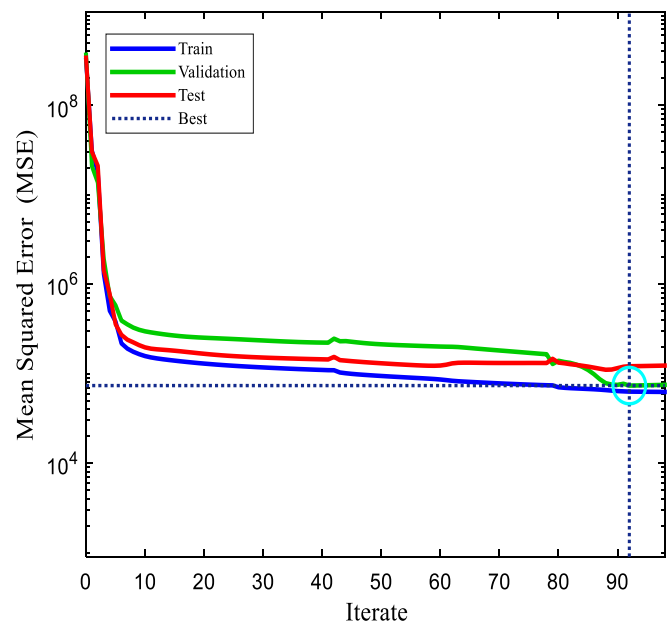

Fig. 5. Performance of ANN model for Nusselt.

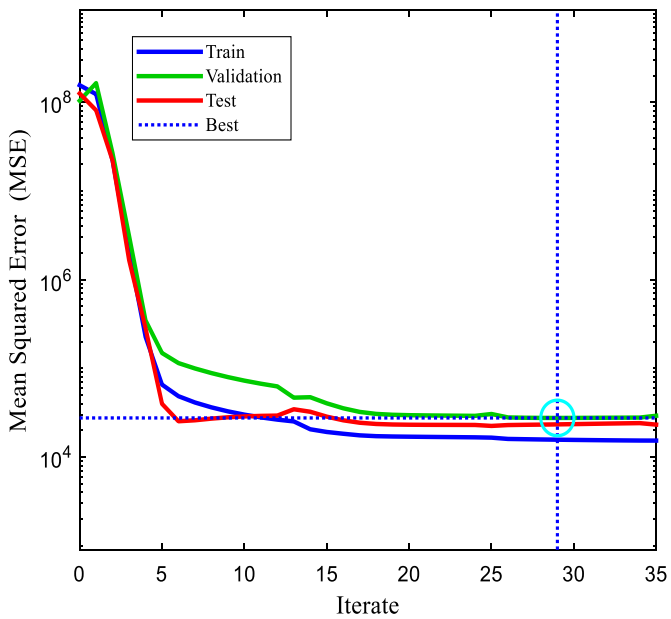

Fig. 6. Performance of ANN model for Thermal Conductivity.

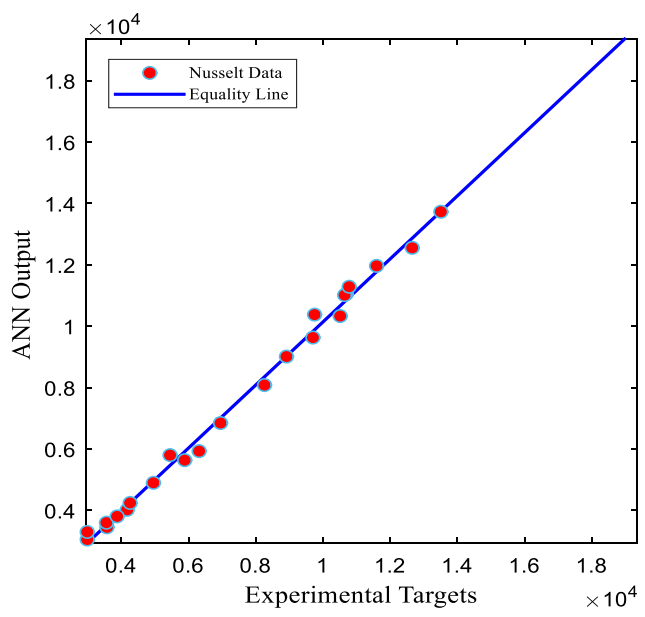

Fig. 7. Regression of ANN results for Nusselt.

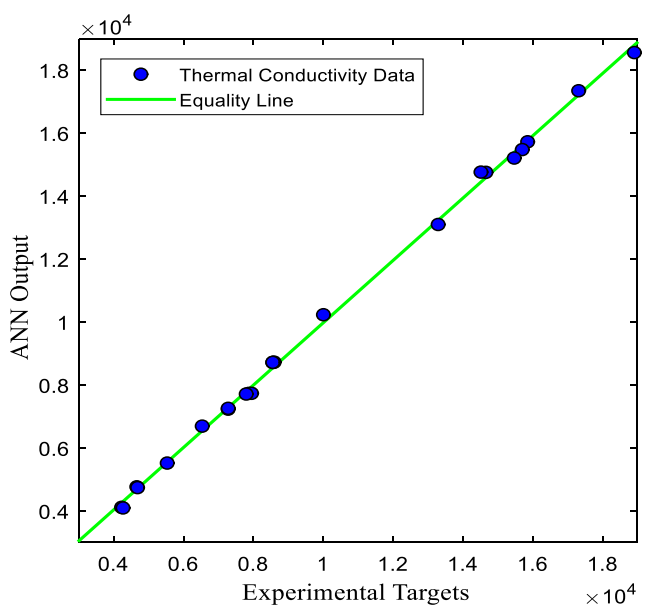

Fig. 8. Regression of ANN results for Thermal Conductivity. 


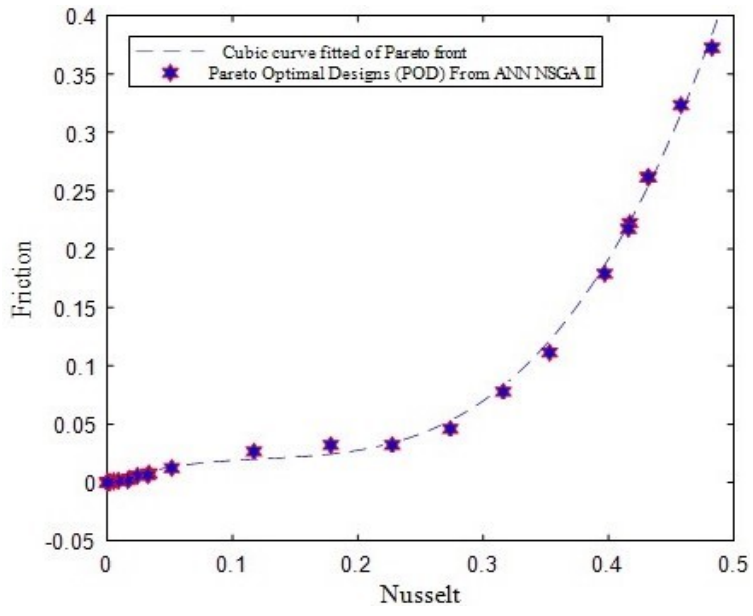

Fig. 9. Pareto optimal front.

New Experimental Relation:

Reynolds $=\mathrm{p}_{1} \times \mathrm{z}^{3}+\mathrm{p}_{2} \times \mathrm{z}^{2}+\mathrm{p}_{3} \times \mathrm{z}+\mathrm{p}_{4}$

$\mathrm{Z}=$ Thermal Conductivity

where $\mathrm{z}$ is centered and scaled:

$\mathrm{z}=(\mathrm{x}-\mu) / \sigma$

$\mu=0.17464$

$\sigma=0.20176$

Coefficients:

$\mathrm{p}_{1}=0.062264$
$\mathrm{p}_{2}=0.045254$
$\mathrm{p}_{3}=0.021934$
$\mathrm{p}_{4}=0.023925$

$\mathrm{y}=0.062 \times \mathrm{z}\{3\}+0.045 \times \mathrm{z}\{2\}+0.022 \times \mathrm{z}+0.024$

where $\mathrm{z}=(\mathrm{x}-0.17) / 0.2$

Norm of Residuals $=0.025287$

\section{Conclusion}

In this study aims to optimize nanofluids to reduce the coefficient of friction and increase the Nusselt number. This optimization was performed by determining the objective functions and experimental data of friction coefficient and Nusselt number of nanofluids and using an artificial neural network method. In this research, the neural network method with input data of Reynolds number (3000 to 18000) and volume fraction $(0.0625$ to $0.2 \%)$ to determine the coefficient of friction and Nusselt number. After the variables and objective functions are defined in the NSGA-II method, multiobjective optimization is performed and the friction coefficient and Nusselt number answers are introduced on the Pareto front. The results show that the Nusselt number improves with the increasing volumetric concentration of nanoparticles as well as the Reynolds number. This increase is due to the higher effective thermal conductivity of the nanofluid as well as the enhancement of the nanoparticle mixing. Among the obtained results, the points with the highest Nusselt number and the lowest coefficient of friction have been selected as the best points.

\section{REFERENCES}

[1] Jordan, A., Scholz, R., Wust, P., Fähling, H., \& Felix, R. (1999). Magnetic fluid hyperthermia (MFH): Cancer treatment with $\mathrm{AC}$ magnetic field induced excitation of biocompatible superparamagnetic nanoparticles. Journal of Magnetism and Magnetic materials, 201(1-3), 413-419. https://doi.org/10.1016/S0304-8853(99)00088-8

[2] Wang, X., Xu, X., \& Choi, S. U. (1999). Thermal conductivity of nanoparticle-fluid mixture. Journal of thermophysics and heat transfer, 13(4), 474-480. https://doi.org/10.2514/2.6486

[3] Xuan, Y., \& Li, Q. (2000). Heat transfer enhancement of nanofluids. International Journal of heat and fluid flow, 21(1), 58-64.

https://doi.org/10.1016/S0142-727X(99)00067-3

[4] Choi, S. U. S., Zhang, Z. G., Yu, W., Lockwood, F. E., \& Grulke, E. A. (2001). Anomalous thermal conductivity enhancement in nanotube suspensions. Applied physics letters, 79(14), 2252-2254. https://doi.org/10.1063/1.1408272

[5] Paul, G., Philip, J., Raj, B., Das, P. K., \& Manna, I. (2011). Synthesis, characterization, and thermal property measurement of nano-A195Zn05 dispersed nanofluid prepared by a two-step process. International Journal of Heat and Mass Transfer, 54(15-16), 3783-3788.

https://doi.org/10.1016/j.ijheatmasstransfer.2011.02.044

[6] Suresh, S., Venkitaraj, K. P., Selvakumar, P., \& Chandrasekar, M. (2011). Synthesis of Al2O3-Cu/water hybrid nanofluids using two step method and its thermo physical properties. Colloids and Surfaces A: Physicochemical and Engineering Aspects, 388(1-3), 4148.

https://doi.org/10.1016/j.colsurfa.2011.08.005

[7] Alarifi, I. M., Nguyen, H. M., Naderi Bakhtiyari, A., \& Asadi, A. (2019). Feasibility of ANFIS-PSO and ANFISGA models in predicting thermophysical properties of A12O3-MWCNT/oil hybrid nanofluid. Materials, 12(21), 3628.

https://doi.org/10.3390/ma12213628

[8] Abdollahi-Moghaddam, M., Motahari, K., \& Rezaei, A. (2018). Performance characteristics of low concentrations of $\mathrm{CuO} /$ water nanofluids flowing through horizontal tube for energy efficiency purposes; an experimental study and ANN modeling. Journal of Molecular Liquids, 271, 342352.

https://doi.org/10.1016/j.molliq.2018.08.149

[9] Amani, M., Amani, P., Bahiraei, M., \& Wongwises, S. (2019). Prediction of hydrothermal behavior of a nonNewtonian nanofluid in a square channel by modeling of thermophysical properties using neural network. Journal of Thermal Analysis and Calorimetry, 135(2), 901-910. https://doi.org/10.1007/s10973-018-7303-y

[10] Said, Z., Abdelkareem, M. A., Rezk, H., \& Nassef, A. M. (2019). Fuzzy modeling and optimization for experimental thermophysical properties of water and ethylene glycol mixture for $\mathrm{Al} 2 \mathrm{O} 3$ and $\mathrm{TiO} 2$ based nanofluids. Powder Technology, 353, 345-358. https://doi.org/10.1016/i.powtec.2019.05.036

[11] Han, H., Yu, R., Li, B., Zhang, Y., Wang, W., \& Chen, X. (2019). Multi-objective optimization of corrugated tube with loose-fit twisted tape using RSM and NSGA-II. International Journal of Heat and Mass Transfer, 131, 781794.

https://doi.org/10.1016/j.ijheatmasstransfer.2018.10.128

[12] Subramanian, R., Kumar, A. S., Vinayagar, K., \& Muthusamy, C. (2019). Experimental analyses on heat transfer performance of $\mathrm{TiO} 2-$ water nanofluid in doublepipe counter-flow heat exchanger for various flow regimes. Journal of Thermal Analysis and Calorimetry, 1-10 https://doi.org/10.1007/s10973-019-08887-1 
[13] Ebrahimi-Moghadam, A., Mohseni-Gharyehsafa, B., \& Farzaneh-Gord, M. (2018). Using artificial neural network and quadratic algorithm for minimizing entropy generation of Al2O3-EG/W nanofluid flow inside parabolic trough solar collector. Renewable energy, 129, 473-485. https://doi.org/10.1016/j.renene.2018.06.023

[14] Tajik Jamal-Abadi, M., \& Zamzamian, A. H. (2013) Optimization of thermal conductivity of $\mathrm{Al} 2 \mathrm{O} 3$ nanofluid by using ANN and GRG methods. International Journal of Nanoscience and Nanotechnology, 9(4), 177-184. http://www.ijnnonline.net/article 4165.html

[15] Bagherzadeh, S. A., Sulgani, M. T., Nikkhah, V., Bahrami, M., Karimipour, A., \& Jiang, Y. (2019). Minimize pressure drop and maximize heat transfer coefficient by the new proposed multi-objective optimization/statistical model composed of "ANN+ Genetic Algorithm" based on empirical data of $\mathrm{CuO} /$ paraffin nanofluid in a pipe. Physica A: Statistical Mechanics and its Applications, 527, 121056. https://doi.org/10.1016/j.physa.2019.121056

[16] Rostami, S., Toghraie, D., Esfahani, M. A., Hekmatifar, M. $\&$ Sina, N. (2020). Predict the thermal conductivity of $\mathrm{SiO}$ 2/water-ethylene glycol (50: 50) hybrid nanofluid using artificial neural network. Journal of Thermal Analysis and Calorimetry, 1-10.

https://doi.org/10.1007/s10973-020-09426-z

[17] Petrudi, A. M., Fathi, P., \& Rahmani, M. (2020). Multiobjective Optimization to Increase Nusselt Number and Reduce Friction Coefficient of Water/Carbon Nanotubes via NSGA II using Response Surface Methodology. Journal of Modeling and Simulation of Materials, 3(1), 1-14. https://doi.org/10.21467/jmsm.3.1.1-14
[18] Petrudi, A. M., \& Scurtu, I. C. (2020). Investigating and Modeling the Factors Affecting Thermal Optimization and Dynamic Viscosity of Water Hybrid Nanofluid/Carbon Nanotubes via MOPSO using ANN. Technium: Romanian Journal of Applied Sciences and Technology, 2(3), 108114.

https://www.techniumscience.com/index.php/technium/art icle/view/575

[19] Johnson, M. D., Tauritz, D. R., \& Wilkerson, R. W. (2007, July). SNDL-MOEA: stored non-domination level MOEA. In Proceedings of the 9th annual conference on Genetic and evolutionary computation (pp. 837-844). https://doi.org/10.1145/1276958.1277123

[20] Filatovas, E., Kurasova, O., \& Sindhya, K. (2015). Synchronous R-NSGA-II: an extended preference-based evolutionary algorithm for multi-objective optimization. Informatica, 26(1), 33-50.

https://content.iospress.com/articles/informatica/inf1049

[21] Yandamuri, S. R., Srinivasan, K., \& Murty Bhallamudi, S. (2006). Multiobjective optimal waste load allocation models for rivers using nondominated sorting genetic algorithm-II. Journal of water resources planning and management, 132(3), 133-143.

https://doi.org/10.1061/(ASCE)07339496(2006)132:3(133)

[22] Mitchell, M. (1996). An introduction to genetic algorithms mit press. Cambridge, Massachusetts. London, England, 1996.

[23] Petrudi, A. M., \& Rahmani, M. (2020). Validation and Optimization of Thermophysical Properties for Thermal Conductivity and Viscosity of Nanofluid Engine Oil using Neural Network. Journal of Modeling and Simulation of Materials, 3(1), 53-60. https://doi.org/10.21467/jmsm.3.1.53-60

[24] Heaton, J. (2018). Ian goodfellow, yoshua bengio, and aaron courville: Deep learning.

https://doi.org/10.1007/s10710-017-9314-z 